\title{
Fundamentos del concepto de guerra generalizada en la Doctrina de Seguridad Nacional (o el influjo de Von Clausewitz y de Ludendorf en Iberoamérica)
}

\section{Basic principles of generalized war in National Security Doctrine (or Von Clausewitz and Ludendorf's influence in Latin America)}

Pedro Rivas Nieto. Universidad Pontificia de Salamanca

Recibido: 10-I-2012 - Aceptado: 25-VII-2012

Resumen:

En este artículo se estudia un concepto esencial para la organización de la Doctrina de Seguridad Nacional: la guerra generalizada. El concepto se construyó a partir de la síntesis de otros previos: la guerra absoluta de Von Clausewitz, la guerra total de Eric Ludendorff y la guerra atómica de los años más duros de la Guerra Fría. En el artículo se estudia la confusa naturaleza que aquellos términos tenían, los errores teóricos de quienes orquestaron la Doctrina de Seguridad Nacional, la valoración desmedida de los estudiosos clásicos de la guerra y la interpretación forzada de la realidad política y social del momento, que justificó ciertos excesos de los regímenes de Seguridad Nacional.

Palabras clave:

Guerra generalizada, guerra absoluta, guerra atómica, guerra fría, Doctrina de Seguridad Nacional, fuerzas armadas.

\section{Abstract:}

This paper analyzes the concept of generalized war, which played a key role in the development of the National Security Doctrine. The interpretation of generalized war by theorists of National Security Doctrine mixed different previous ideas: absolute war-from Von Clausewitz-, total war-from Eric Ludendorff-and atomic war-from Cold War times-. This paper studies the confusing nature of such concepts: the theoretical misconceptions, the excessive enthusiasm that war generated among classical theorists and the forced interpretation of political and social realities, which gave way to a justification of the excesses of the National Security regimes.

Keywords:

Generalized War, Absolute War, Atomic War, Cold War, National Security Doctrine, Armed Forces. 


\section{Introducción}

Gaston Bouthoul, el creador del vocablo polemología $a^{1}$ como ciencia que estudia las formas, causas, efectos y funciones de la guerra, creía que no era posible una definición unívoca del término guerra porque eso significaría que se conocía a la perfección el fenómeno y, dada su cambiante y tortuosa naturaleza, era -y es- imposible. Grocio decía que la palabra griega polemos derivaba de poles, que designa a un gran número de gente y recordaba que el vocablo latino bellum, derivado de duellum, que Horacio y Plauto empleaban para designar la guerra, significa bis de duis (Grocio, 1925: cap. 1). Fuere como fuere, Bouthoul, quizá el más brillante estudioso del siglo XX de este fenómeno, definía la guerra como una lucha armada y sangrienta entre agrupaciones organizadas. La guerra-decía- es una forma de violencia metódica y organizada respecto a los grupos que la hacen y que la dirigen; está limitada en el tiempo y en el espacio y sometida a ciertas reglas jurídicas, cambiantes según los tiempos y los lugares; y cuando no se pierden vidas humanas, se vuelve un simple intercambio de amenazas (Bouthoul, 1971: 35). Esto, grosso modo, es la guerra.

No se descubre nada nuevo con estas afirmaciones introductorias, pero lo que interesa a este artículo es una sección específica del fenómeno de la guerra en la contemporaneidad -la guerra generalizada- y su aplicación a la Doctrina de Seguridad Nacional que se implantó en Iberoamérica en parte del último tercio del siglo XX. En este artículo se estudiarán los fundamentos políticos, históricos y -aunque sea de soslayo- filosóficos en los que se basó un concepto bélico esencial para entender parte de los razonamientos de la desaparecida Doctrina de Seguridad Nacional.

Es necesario analizar la noción de guerra generalizada con un enfoque multidisciplinar. La razón es la siguiente: si bien es cierto que el concepto en América Latina es aplicable sólo a un período concreto tanto de la historia universal como de la continental -el de los años de la Guerra Fría y de su reflejo en Iberoamérica- y a priori requeriría de un enfoque histórico y de fuentes y procedimientos propios de la Historia, al mismo tiempo su estudio remite a las ciencias sociales, pues es necesario indagar en la concepción que los científicos sociales de los Estados Unidos y de América Latina tenían del fenómeno bélico. Fueron ellos quienes lo construyeron a partir de doctrinas previas nacidas en Europa -algunas de ellas orquestadas por filósofos- y de experiencias bélicas dirigidas por países europeos. Por si fuera poco, la misma naturaleza compleja y diversa del objeto estudiado -una sección del viejo problema de la guerra- dificulta acercarse a él desde una sola rama del saber.

\section{La guerra generalizada (o la síntesis de guerra absoluta y guerra atómica)}

Según John M. Collins, que tenía en cuenta lo dicho por el Consejo de Jefes de Estado Mayor de los Estados Unidos, la guerra generalizada era el conflicto armado entre las potencias mayores en la cual se empleaban los recursos totales de los

1 Lo inventó en 1946 para estudiar la guerra más como un problema social que como la "ciencia de la guerra" que tradicionalmente se enseñaba en las escuelas militares y en los estados mayores. 
beligerantes y la supervivencia nacional de uno de ellos estaba en peligro (Collins, 1970). El ejemplo más claro era una guerra entre la Unión Soviética y los Estados Unidos.

Esta idea era bastante clara porque la noción de guerra generalizada trataba de fusionar dos conceptos distintos; el que define la guerra por su fin y el que la define por sus medios. El primero -que sigue las ideas de Von Clausewitz- es el concepto de guerra absoluta, es decir, la guerra por la supervivencia hasta la destrucción total del adversario ${ }^{2}$. El segundo es el de la guerra atómica: es la guerra que destruye al adversario no porque ese sea su fin, sino porque los medios empleados son tales que lo único que logran es la destrucción total. La Destrucción Mutua Asegurada (MAD, eran sus siglas en inglés ${ }^{3}$ ), doctrina por excelencia de los años del "equilibrio del terror" implicaba, tal y como su nombre indica sin ambages, la desaparición de los contendientes, esto es, la destrucción de entre un 50 y un 70\% de su capacidad industrial y de entre un 33 y un 40\% de su población (Martínez, 2001: 465-466). La paz se hacía crecientemente imposible, pero la guerra era alarmantemente peligrosa. El general Montgomery, héroe de la Segunda Guerra Mundial, lo repitió unas cuantas veces: "la guerra abierta entre los Estados poderosos o los grupos de Estados sería un método [...] negativo. No resultaría de ello sino la completa autodestrucción de las naciones afectadas" (Pavón, 1971: 71).

Quienes estudiaron los asuntos de la guerra atómica -y crearon las escuelas más conocidas- fueron estadounidenses. Los militares franceses enriquecieron el debate nuclear al incluir complejidad al sistema con el "tercer centro de decisión", la force de frappe francesa, cuyo origen se remonta a la IV República -en concreto a la etapa de Pierre Mendes-France-la cual fue anunciada por De Gaulle en su discurso a la nación del 3 de noviembre de 1959. Era una fuerza de choque -cuya base debía ser un arma atómica- susceptible de ser desplegada en cualquier momento y lugar que, aplicando un modelo de respuesta automática, fuera capaz de causar graves daños a un eventual agresor y, de este modo, disuadirle de atacar territorio francés (Ramírez, 1983: 475-481). De esta manera el país garantizaba su defensa mediante el hipotético uso del arma nuclear y, al mismo tiempo, estratégicamente se situaba entre las superpotencias (Delmas, 1970: 156-157). A partir de los años sesenta, oficiales soviéticos confeccionaron también la doctrina nuclear soviética, inspirada en todo punto por el razonamiento marxista y con la clara conciencia de la importancia política que contiene toda doctrina militar (Martínez, 2001: 479). No en vano en la URSS se comenzó con publicaciones clasificadas y a partir de 1962, con la aparición de la obra Estrategia Militar de Sokolowsky, se hicieron públicas las ideas soviéticas sobre la doctrina nuclear. Así que autores como Brodie o Kahn en los Estados Unidos, Beaufre o Poirier en Francia, o el mariscal Sokolowski en la Unión Soviética fueron los creadores de la doctrina de la guerra atómica.

2 Esto es: el fin de este tipo de guerra es la destrucción total del adversario. Si se mantiene la distinción clásica entre el bellum hostile y el bellum romanum, la guerra de la que se habla en este estudio sería una versión moderna y recrudecida de esta última.

3 Nótese lo que significa el acrónimo en inglés: loco, enfadado, malsano... idea que puede definir lo enfebrecido de la doctrina. 
En realidad, mezclar los conceptos de guerra absoluta y guerra atómica para sintetizarlos en uno no aportaba nada, pues si bien es posible la guerra de destrucción total por los medios -la guerra atómica- no lo es la guerra absoluta, que no es una guerra real, sino un concepto abstracto del cual no se encuentran realizaciones humanas. Es más, es probable que la fusión de la idea de guerra absoluta con la de guerra atómica no fuera muy acertada porque la lógica de Clausewitz perdió vigencia tras la Segunda Guerra Mundial. Su idea de buscar el choque decisivo no era posible en la era del equilibrio nuclear (Sohr, 2003: 13-14), pues podía suponer la desaparición de la especie humana, algo que el oficial prusiano no pretendió jamás. Por tanto, la definición de guerra generalizada era ambigua al apartarse de las definiciones clásicas y deformarlas, y no es absurdo pensar que semejante ambigüedad fuera -en el tiempo del establecimiento de la Doctrina de Seguridad Nacional- el origen de muchas ambigüedades militares iberoamericanas (Comblin, 1979: 35).

Téngase en cuenta que una guerra absoluta escapa a la conducción política porque en sí misma lleva su propio fin; es decir, es una guerra ciega porque no tiene límites ni control. En realidad expresa lo ilimitado y absoluto -en abstracto-del fenómeno bélico, que no tiene límite en el espacio, en el tiempo ni en los medios humanos. Aron afirmaba que la guerra absoluta respondía al concepto, a la guerra separada de sus orígenes y de su fin, separada de la política como condición o finalidad. No hay guerra absoluta en la realidad, sólo existe en el mundo del concepto, de lo ideal (Aron, 1993a: 114). El empeño por destruir al enemigo es absoluto y todo se subordina al esfuerzo bélico. La violencia llevada al extremo terminaría con la destrucción absoluta de una de las partes o, presumiblemente, de ambas. Como hacía notar Clausewitz, la guerra abandonada a sí misma tiende a ser absoluta pero las guerras reales no son así. Y no lo son porque el hombre es razonable y somete la guerra a fines racionales. Las guerras reales hacen enfrentarse a grupos, a colectividades, cada una de las cuales se unifica y se exterioriza en una sola voluntad. Nunca es totalmente ofensiva ni defensiva, sino una combinación de ambas. La guerra ciega no es más que el suicidio colectivo, por eso se somete a la política, a fines que le imponen límites. Por tanto, una guerra generalizada -una guerra entre la Unión Soviética y los Estados Unidos, que es lo que se temía en aquellos años- habría sido -y sería siempre- el fin de la política y de la raza humana.

Cabría preguntarse entonces por qué se intentó una definición híbrida de guerra generalizada. La respuesta puede ser, quizá, la siguiente: porque permitía legitimar a los regímenes de Seguridad Nacional implantados en el Cono Sur después de los años sesenta y setenta del siglo XX. Téngase en cuenta que si la guerra era de destrucción total debido a los medios que se empleaban y a sus fines debía evitarse como fuera, pues el único resultado que se obtenía de participar en ella era el horror desmedido. Así que los medios cuyo fin fuera evitar ese tipo de guerra se reforzaban y recibían nuevos argumentos. En su peculiar lógica más valía cierto grado de exceso que el horror de ese tipo de guerra. Era mejor acabar con algunos inocentes y pecar por exceso que permitir, por pudores absurdos e irresponsables, la desaparición de toda la especie humana. Ante el enemigo comunista que -según los doctrinarios de la Seguridad Nacional- se infiltraba en todos lados sólo cabía una respuesta contundente para garantizar la seguridad de todos y la paz futura. De esta manera los regímenes autoritarios se justificaban. 


\section{Deslices terminológicos y faltas conceptuales: la herencia de Carl Von Clausewitz y de Eric Ludendorff}

El mismo Clausewitz fue el origen de muchos de estos equívocos, aunque podría decirse que apenas se comprendió su obra y su pensamiento. Junto con Marx y Darwin fue una de las figuras más importantes del siglo XIX y no fue en absoluto un apologista de la guerra, sino un estudioso de sus medios, sus causas y de todos sus aspectos (Bouthoul, 1970b: 87). Quizá lo que más claro se tiene de su obra es la idea de que la guerra es un acto de violencia para obligar al contrario a hacer nuestra voluntad (Von Clausewitz, 2005: 17). Su pensamiento sintetizó el esfuerzo intelectual de toda una época (Aron, 1993a: $333^{4}$ ) y fue más un filósofo que un tratadista militar. Se había independizado de los postulados clásicos porque pensaba que la teoría de la guerra de Maquiavelo estaba demasiado influida por los escritores antiguos -como el clásico pensamiento chino del siglo IV a.C. de Sun Tzu reflejado en El arte de la guerra- y el italiano fue revolucionario al pensar que la guerra debía vincularse directamente con el arte de gobernar (Gilbert, 1986: 31).

Para Maquiavelo la guerra era una táctica transitoria que debía aplicarse cuando las intrigas de la diplomacia y de la corte no surtían efecto. Su realismo le llevaba a pensar que era preferible un tratado de paz a una guerra permanente, costosa en todos los órdenes y especialmente para el Príncipe, al cual un pueblo desesperado por el hambre y por la muerte de sus seres queridos podría llegar a derrocar. Toda su obra Del arte de la guerra es un tratado orientado a esto. Por eso pensaba que un ejército bien organizado, es decir, de súbditos y no de mercenarios, podía lograr los fines del gobernante (Maquiavelo, 19985). Por otro lado, Von Clausewitz creía que un buen jefe militar no debía guiarse por reglas estrictas, sino tener ideas claras sobre la guerra absoluta que le permitieran extraer conceptos adecuados de la guerra real para adaptarse bien a las circunstancias (2005). Por eso, De la guerra no era un tratado técnico ni una guía del oficial en campaña, sino un hallazgo del pensamiento militar ilustrado. No obstante, se convirtió en un breviario estratégico utilizado en todos los tiempos (Cardona, 2005: XX). De ahí que el pensamiento de Von Clausewitz estuviera en el origen del sistema moderno de conceptos de la guerra (Liddell Hart, 1931: 1216). Si el clásico Sun Tzu pensaba que la guerra debía ser una posibilidad -no llevada a cabo en la medida de lo posible- para preservar una paz duradera, y Maquiavelo la asumía como una eficaz estrategia para negociar una paz ventajosa, Von Clausewitz la entendía como una lucha ilimitada que establecía una nueva forma de relaciones humanas. De esa manera las guerras que comenzaron con la Revolución Francesa y que se desarro-

4 Aron asegura que Von Clausewitz pertenece más al siglo XVIII que al XIX. "Permanece fiel a los pensadores de las Luces, aunque, despertado con el trueno de la Revolución, encuentra espontáneamente los acentos de la pasión nacional”. Del mismo modo, Aron creía que Von Clausewitz había sido influido por El espíritu de las leyes de Montesquieu.

5 Cabe quizá recordar que no era sólo un teórico, sino que pretendía dar consejos prácticos a los gobernantes de las ciudades italianas renacentistas.

6 Quizá errado a veces, como entrevió Liddell Hart. El alemán extendió la idea de la guerra a ultranza. Si un Estado utiliza sus fuerzas hasta el límite de su agotamiento, condena a su propia política a la debilidad. Y si según Clausewitz la guerra es la continuación de la política por otros medios, está dirigida pensando en las ventajas de la posguerra. Luego, ¿no entraña esto una contradicción peligrosa? 
llaron con las campañas napoleónicas le permitieron distinguir las guerras limitadas -hechas por los príncipes del siglo XVIII- y las guerras absolutas -las que destruyen totalmente al adversario-- Eran estas la realidad de las guerras revolucionarias y napoleónicas. Von Clausewitz lo decía sin ambages ${ }^{7}$. Al prusiano le marcó la brutalidad de las Guerras Napoleónicas, definidas por Jefferson como una pugna entre el tirano de tierra-Francia-y el del océano -Inglaterra- (Tucker y Hendrickson, 1990: 148).

Clausewitz creía que esas nuevas guerras eran el modelo de guerra del futuro. Sin embargo, se dio cuenta de que las guerras nunca son absolutas sino limitadas, por mucha violencia que desplieguen. Las guerras revolucionarias -las primeras guerras nacionales y democráticas- incorporaron elementos nuevos al arte de la guerra que parecían cambiar su esencia misma. El primer elemento nuevo que agregaron estas nuevas guerras fue la movilización total, que es lo propio de un tiempo revolucionario. Durante el Antiguo Régimen los recursos limitados impedían disponer de mucho material y de hombres. Tras la Revolución Francesa la concentración de riqueza y de poder en el Estado permitía transformar el sistema anterior y aumentar los recursos y el número de combatientes. Los logros de la revolución agrícola y demográfica permitieron disponer de alimentos y hombres a gran escala, además de estar a las puertas de una revolución social y técnica. Fue precisamente allí donde estos éxitos no se lograron-España y Rusia- donde Napoleón fracasó. Y fue así, precisamente, por la paradoja que creaba la nueva forma de lucha revolucionaria: la guerra penetró por vez primera y por completo en la sociedad y generó el alzamiento de las poblaciones contra el invasor, algo que no ocurría cuando las guerras eran sólo de príncipes, y no de naciones. Esta idea indica que el surgimiento de las nacionalidades en Europa enlaza con el despliegue de violencia ilimitada llevado a cabo por los ejércitos revolucionarios: al atacar a toda la población, ésta se rebela de forma total contra los ocupantes y aplica todas las formas de lucha que encuentra para defenderse. España es el ejemplo claro. Las tropas del rey y las guerrillas patrióticas diezmaron a un ejército, el napoleónico, que no había respetado las artes de la guerra y había generado que su violencia se volviera contra ellos. Esta idea enlaza con la que viene a continuación.

El segundo elemento nuevo fue que el hecho de la "nación en armas" hizo de la guerra un compromiso de todo el pueblo. El grito revolucionario por excelencia, “ ‘Ciudadanos, a las armas!”, era el símbolo de la nueva condición adquirida por los hombres libres revolucionarios. Participar en la batalla era un logro democrático porque los hombres eran ya ciudadanos y la guerra era un derecho y un deber de quienes ostentaban esa nueva cualidad. Además se le hizo creer al pueblo que lo que estaba en juego en esas guerras no eran intereses materiales, sino la propia supervivencia. Por tanto las guerras nacionales se iban a vivir como guerras por la supervivencia. La guerra, en la psique personal y colectiva, ya era absoluta. La

\footnotetext{
"Se podría dudar de que nuestra idea de la esencia absoluta que le corresponde tuviera alguna realidad, si no hubiéramos visto precisamente en nuestros días la verdadera guerra en esa absoluta perfección. Tras una breve introducción, llevada a cabo por la Revolución Francesa, el brutal Bonaparte la llevó rápidamente a ese punto. Bajo su mando, se avanzaba sin descanso hasta que el enemigo sucumbía; y casi también sin descanso se producían los contragolpes. ¿No es natural y necesario que esta manifestación nos devuelva al concepto original de la guerra, con todas sus rigurosas consecuencias?" (Von Clausewitz, 2005: 638).
} 
Revolución Francesa arrastró a todo el pueblo a participar en la guerra, dio a ésta su carácter extremo y reveló la naturaleza de la guerra absoluta (Aron, 1993a: 420). Precisamente las campañas napoleónicas fomentaron las nacionalidades y el nacionalismo en Europa porque la violencia se dirigía contra el pueblo y no contra el príncipe, que era lo propio de la guerra del tiempo de la Ilustración. La idea hermosamente expresada en la frase "la tierra se arma contra el invasor", acuñada tras los avances napoleónicos por el suelo europeo, da idea de lo que supuso la violencia del naciente tiempo democrático. En la Guerra de la Independencia de España, seguida con interés por los demás países del continente por lo que tenía de revelador para su propia supervivencia, se ahogaron las particularidades y se fomentó la unidad nacional. El mismo Von Clausewitz lo decía con otras palabras ${ }^{8}$. La guerra absoluta implicaba el ascenso a los extremos.

La deducción inmediata que se extrae de estos principios es que las guerras del siglo XX iban a ser una especie de cruzada secularizada en la que la supervivencia de la "república", de las instituciones o de las creencias equivalía a la supervivencia del pueblo; iban a ser "absolutas" y a prolongarse hasta la destrucción total del adversario ${ }^{9}$-imposible, se ha visto- o hasta la capitulación total de uno y la victoria total del otro.

La Gran Guerra se vivió como una reanudación de las guerras napoleónicas. Desde 1814 hasta 1914 Europa vivió un siglo de paz, como bien observaron Salisbury y Churchill. Los mandos de las fuerzas armadas en la Primera Guerra Mundial se decían discípulos de Napoleón y de Von Clausewitz y se deseaba una guerra de nación contra nación por la supervivencia y hasta la derrota total del contrario, como si se hubieran olvidado las palabras de Napoleón que rezaban: "Toda guerra entre europeos es una guerra civil". Las ideas del prusiano fueron impregnando a todo el estamento militar europeo y en 1914 sus planteamientos eran clausewitzianos. Después de la Primera Guerra Mundial se decía que Clausewitz, dado su desmedido influjo, había engendrado la catástrofe, y Liddell Hart, no sin sorna, lo llamó el Madhi de la masa y de las matanzas mutuas (Liddell Hart, 1931: 118-129). Fuere como fuere, la guerra sirvió para desarrollar aún más la teoría de la guerra absoluta.

Ludendorf, el gran vencido de la Gran Guerra, popularizó la teoría de la guerra total, relevo importante en el camino que condujo al concepto estadounidense de la guerra generalizada. Más que crearla, la difundió y la glorificó. Él sabía que su

8 "En el siglo XVIII, en tiempos de las Guerras Silesias, la guerra era aún una mera cuestión de gabinete, en la que el pueblo sólo participaba como ciego instrumento; a principios del XIX estaban en la balanza los pueblos de ambas partes. Los generales que se enfrentaban a Federico el Grande eran hombres que actuaban por encargo, y por eso mismo hombres en los que la cautela era un rasgo de carácter predominante; el adversario de austriacos y prusianos era, por decirlo en pocas palabras, el propio Dios de la guerra" (Von Clausewitz, 2005: 642).

9 Y se ve muy claramente incluso en este siglo XXI. Sin ir más lejos así parece haberlo hecho la denominada Doctrina Bush, cuando afirma que el enemigo al que se enfrentan actualmente los EE.UU. -el terrorismo transnacional de alcance mundial- no tiene ni régimen político, ni ideología, ni religión, ni cuerpo concreto. Ese enemigo es el mal absoluto. Esta concepción de "guerra cósmica" de corte apocalíptico, en donde la única opción posible es borrar del mapa al enemigo si se ansía vivir en paz, muestra las características mencionadas en el texto (Rey y Rivas, 2007: 21-37). 
concepción se oponía a la de Clausewitz y deseaba que así fuera, pues criticaba a Von Clausewitz por quedarse corto en la idea de la violencia ilimitada. Von Clausewitz no distinguía conceptualmente política, dirección de la guerra y estrategia (Aron, 1993a: 46), pero Ludendorf contravino un principio esencial en Alemania cuando dijo que De la guerra pertenecía a una época caduca y que la política era la que debía ponerse al servicio de la guerra, y para ello preconizaba una especie de dictadura del comandante en jefe. Él creía que toda la nación es objeto y sujeto de la lucha, en lo material y en lo moral. Si la guerra era la expresión más alta de la "voluntad de vivir" y la prueba suprema de los pueblos, en la guerra la nación debía poner todo al servicio de aquella, y en la paz ponerlo todo al servicio de la próxima guerra ${ }^{10}$. Con la mentalidad propia de un espíritu totalitario insistía en que había que lograr la unidad psíquica del pueblo -pues el espíritu de sacrificio de la nación daba a los soldados moral de vencedor- e incluso suprimir a los disidentes, a quienes concibieran ideas diferentes de las del Mando Supremo.

Ludendorf decía que "los pueblos no tienen el sentido de la guerra de agresión. Pero admiten la lucha por la vida y ven fácilmente una voluntad de agresión en una declaración de guerra” (Ludendorf, 1936: 177-178). En la guerra moderna había de participar el pueblo, al que había que formar sistemáticamente, y Ludendorf basaba esta exigencia en consideraciones metafísicas, pues afirmaba que la guerra era la expresión suprema de vida de la raza. La victoria debía ser radical mediante un ataque dirigido a los puntos débiles del enemigo, bien en un solo ataque, bien en varios ataques violentos. Para ello era necesario usar todos los medios disponibles, los militares, los diplomáticos, los económicos, los psicológicos, tanto en el interior como en el exterior. Esto era la guerra total, que designaba los caracteres propios de la Primera Guerra Mundial. De ahí que toda la política -por tanto, todo el Estado- debiera estar al servicio de la guerra. Y, por supuesto, esto necesitaba un sistema económico nacional autárquico que pudiera adaptarse a lo que pedía la guerra totalitaria. La guerra tenía que ser absoluta y así se la debía desear. Según Ludendorf, la guerra se perdió debido a la traición del pueblo alemán, al que le faltó cohesión y energía. Al final, la voluntad de lucha de la nación estaba ya rota. No fue el ejército, sino la retaguardia la que cedió. De hecho, él fue un hombre atrevido en la dirección militar de la guerra, como lo demuestran sus campañas, en las que aceptaba riesgos calculados y cosechaba éxitos (Liddell Hart, 1946: 242 y ss. ${ }^{11}$ ). De la experiencia de las operaciones aliadas fracasadas dedujo que la táctica debía anteponerse a los objetivos estratégicos aunque, en realidad, sus éxitos tácticos fueron la causa de su ruina.

Este pensamiento sirvió para que en la Segunda Guerra Mundial Hitler se lanzara a una guerra semejante. Conoció tanto la obra como la persona de Ludendorf, entendió la técnica revolucionaria de Lenin, puso al servicio de su alocada visión de la comunidad racial los métodos de agitación del visionario soviético y utilizó el instrumento militar heredado de tiempos pretéritos para un fin más ambicioso que el de Napoleón. Poseía intuición, aunque era proclive a cometer erro-

10 No es una idea original de Ludendorf. Esparta lo intentó y pereció por el daño que se hizo a ella misma.

11 Dice el británico que la verdadera historia de 1915 en el frente oriental fue la lucha de voluntades entre Ludendorf y Falkenhayn. Si se hubieran aplicado los principios del primero los logros habrían sido notables. 
res elementales tanto de acción como de cálculo. La Gran Guerra había sido para él la mayor experiencia de todas las que podía vivir el hombre y había encontrado en las trincheras un peligro enaltecedor. Su hubris, su soberbia sacrílega, era ilimitada. Se quedó a medio camino del mundo moderno, pues seguía pensando que el mando nacía de un sumo sacerdote al que el soldado debía obediencia estricta y que sabía que al hacerlo lograría la victoria (Liddell Hart, 1946: 288). Quiso hacer de la guerra desmesurada ${ }^{12}$ una lucha por la supervivencia del pueblo alemán; pero en la muerte de la política llegó la tragedia, que no previó. Era un clausewitziano convencido, que veía en la guerra una continuación de la política sin entender que entre ambas hay notables diferencias. En plena Segunda Guerra Mundial se vio obligado a continuar la guerra para que el nacionalsocialismo no perdiese su vigor ideológico. Sospechaba que los acuerdos convencionales impedirían la consecución de una sociedad nueva edificada sobre la pureza y el dominio racial (Kershaw, 2000: 341). Eso sí, creía que la aspiración del que dirige la guerra debía ser lograr la capitulación de los ejércitos enemigos sin lucha, al contrario que Ludendorf (Liddell Hart, 1946: 29713). Pero hay algo más. Sólo Hitler y Ludendorf dieron un sentido preciso a lo que Carl Schmitt llamaba "hostilidad absoluta" (Schmitt, 1998). Ambos plantean la comunidad racial como tema de la historia y ven en los enemigos de esta comunidad no sólo a los enemigos del pueblo alemán, sino de todos los pueblos. "Afirmo -dice Aron- que esta hostilidad, y solamente esta, merece la calificación de absoluta porque conduce lógicamente a la masacre o al genocidio" (Aron, 1993b: 194-195). Los conceptos que ambos tenían de raza, Estado y derecho del pueblo alemán a dominar la Tierra eran semejantes. No obstante había notables diferencias entre ellos, pues mientras Ludendorf quería que la estrategia dirigiera la política, Hitler combinó las dos funciones en una sola persona, disfrutando de las mismas ventajas que Alejandro y César en el mundo antiguo y que Federico el Grande y Napoleón en tiempos más recientes (Liddell Hart, 1946: 298 ${ }^{14}$ ).

En la posguerra los contendientes, que habían vencido en la guerra, se lanzaron también a una guerra sin fines políticos, una guerra por la supervivencia y por la victoria total. En los Estados Unidos se consagró la idea de la guerra total, que era una nueva forma de la guerra absoluta (Comblin, 1979: 36). No es baladí, por tanto, la idea de Aron que recordaba que "el carácter total de la guerra depende al mismo tiempo del concepto y de la experiencia. La guerra próxima a su forma absoluta se acerca simultáneamente a su naturaleza original" (Aron, 1993a: 293). Es decir, al no caber teorizaciones desmedidas ni paradigmas al referirse a un tipo de guerra cuyos efectos pudieran suponer la desaparición de millones de vidas o, en el peor de los casos, de la especie humana, la estrategia de la guerra atómica era sencilla, directa y de carácter disuasivo. Era una lógica clausewitziana en la que las armas nucleares podían servir a los fines políticos no porque fueran

12 Caracterizada por el sentimiento de superioridad de la raza germánica, por el mesianismo secularizado y por la confianza en su genio personal.

13 "Las armas revolucionarias, la ética del guerrero y la filosofía de Clausewitz de incorporar lo militar a los fines políticos -asegura Keegan-, estaba todo encaminado a lograr que bajo el mando de Hitler, la guerra en Europa entre 1939 y 1945 alcanzara un nivel absoluto como jamás había soñado caudillo alguno, ni Alejandro, ni Mahoma, ni Gengis Kan, ni Napoleón” (Keegan, 1995: 443).

14 Son palabras escritas en 1940. Téngase esto en cuenta. 
a emplearse, sino por el peligro que su uso representaba. A comienzos de los años sesenta esta idea se veía claramente en la ya citada Destrucción Mutua Asegurada (MAD), en donde se intentaba disuadir al enemigo de un ataque, pues se podía infligir un daño gravísimo a cualquier agresor, incluso después de recibir un primer golpe sorpresa (Lawrence, 1989: 16).

\section{Guerra generalizada en Iberoamérica y Doctrina de Seguridad Nacional}

Todo este abigarrado y confuso pensamiento -la guerra absoluta mezclada con la guerra atómica para definir la guerra generalizada, de naturaleza compleja y difusa al mismo tiempo- se trasladó a Iberoamérica. En ella los teóricos de la Seguridad Nacional citaban constantemente a Ludendorf y parte de sus tesis se apoyaban en él. Es buena muestra el hecho de que el principal libro que escribió Ludendorf, Der totale krieg, se tradujera y publicara en español por primera vez en 1964 con el título La guerra total en la editorial Pleamar de Buenos Aires. Tanto el momento -comienzos de los años sesenta-como el lugar-la Argentina, que fue junto con el Brasil el país de mayor relevancia de la doctrina-son significativos. Sin ir más lejos, uno de los padres de la Doctrina de Seguridad Nacional en el Brasil, el general Golbery de Couto e Silva, menciona a Ludendorf en una de sus más importantes obras, Geopolítica de Brasil. Los devotos de la Seguridad Nacional decían que en la lucha contra el comunismo toda la nación debía involucrarse; que había que emplear cualesquiera medios para debilitar al enemigo; que todo debía estar al servicio de la guerra; que la disidencia era peligrosa para la supervivencia de la nación y, por tanto, había que acabar con ella; y que se necesitaba una economía sólida para contribuir al esfuerzo de guerra. Los partidarios de la Doctrina de Seguridad Nacional abundaban en la idea de la guerra total, que era una lucha por la supervivencia, e idolatraban la idea de seguridad a cualquier precio.

Cabe añadir algunas nociones acerca de la Doctrina de Seguridad Nacional, pues aunque bien conocida por los expertos, no está de más hablar de sus características esenciales comprender mejor la situación en la que surgió. Sobre todo, teniendo en cuenta que no es fácil definirla dada su naturaleza. Si acaso, como ocurre con otros conceptos confusos de la política -como el de terrorismo, que se distingue de la guerra, la delincuencia común o la guerrilla-, cabe acercarse a ella por descarte y por aproximación. En realidad su estudio primero se debe a Joseph Comblin-ya citado en este artículo- un teólogo belga de la Universidad Católica de Lovaina que en una obra publicada en 1977 -y traducida al español en 1979 como La Doctrina de la Seguridad Nacional- sistematizó los elementos esenciales que la caracterizaban: obsesión con perseguir al enemigo comunista, que supuestamente se agazapaba en todos lados; modificación de los atributos de las fuerzas armadas, dedicadas prioritariamente a garantizar el orden interno más que la defensa nacional; aplicación de procedimientos que violaban de forma recurrente los derechos humanos; transformación del pueblo en objeto histórico y no en sujeto; verticalismo organizativo y elitismo del sistema político; asunción de principios económicos emanados de la Escuela de Chicago de los EE.UU. y sumisión a los postulados que el gobierno de ese país entendía esenciales para la seguridad nacional en los tiempos de la Guerra Fría; y, en fin, eliminación de cualquier clase de disidencia. Grosso modo, 
estas características eran las propias de la Doctrina de Seguridad Nacional, cuya identificación continuó haciendo, tras los esfuerzos primeros de Comblin, la Iglesia Católica en el llamado Documento de Puebla de 1979. Gracias a esto se pudo afirmar que la Doctrina de Seguridad Nacional era más una doctrina que una ideología bien definida.

Su paradigma teórico se construyó sobre la marcha, utilizando ideas entresacadas de discursos de los altos mandos militares que la ponían en práctica en algunos países de América, salpicados de consignas morales y de conceptos del arte de la guerra -frecuentemente malinterpretados-, como la guerra absoluta de Von Clausewitz, la guerra total de Ludendorff, o la guerra generalizada del Consejo de Jefes de Estado Mayor de los Estados Unidos (Rivas, 2010: 52-103). Bebía de la doctrina contrainsurgente emprendida por los mandos franceses en la guerra de Argelia tras lo aprendido en Indochina después de estudiar la teoría y la práctica de la guerra revolucionaria; se nutría de la doctrina de la seguridad hemisférica estadounidense y de lo aplicado y aprendido en la guerra de Vietnam; y, en suma, de cualquier aspecto pragmático que conviniera a sus intenciones. En realidad lo más importante de la Doctrina de la Seguridad Nacional no era su definición, sino su ejercicio, pues para tal estaba ideada, como suele ocurrir con las doctrinas de naturaleza militar (López, 1985). Por eso lo propio de esa doctrina, despótica y autocrática, era la ausencia de límites. No tenía límites porque ni sus doctrinarios ni los ciudadanos sabían cuándo se había encontrado un grado suficiente de seguridad. Este principio no es algo exclusivo de ella, pues el deseo de seguridad, por sí mismo, tiende a ser ilimitado. La seguridad absoluta es ambigua y su precio es -recuérdense las palabras de Kissinger-la inseguridad absoluta de los otros (Kalb y Kalb, 1975: 122). En esta situación se hace siempre necesario que la seguridad encuentre en otro principio -la política- sus límites y su justa medida. Pero la Seguridad Nacional no disponía ni de voluntad ni de mecanismo alguno para controlar la tendencia a la seguridad absoluta.

En esta forma de pensar era notoria la influencia de Hobbes. En Geopolítica del Brasil, obra del general Golbery do Couto e Silva y una de las más influyentes para la construcción de la Doctrina de Seguridad Nacional, se intentaba negar la importancia del filósofo británico a la vez que era diáfano su influjo. Refiriéndose a él decía Couto e Silva unas palabras claras $^{15}$. Couto e Silva recordaba que en el último tercio del siglo XX en que vivía el mundo, los peligros que corría el hombre eran incluso mayores que los de tiempos de Hobbes. También creía que la incertidumbre del ciudadano dentro de cada nación y la inseguridad de unos Estados frente a otros, junto a la visión omnipresente de la guerra, dominaban aquellos días y explicaban el ansia neurótica con que la Humanidad se lamentaba “dispuesta incluso a esclavizarse a cualquier amo y a cualquier tiranía, en cuanto le ofrezcan, en un plato de lentejas, un poco de seguridad y de paz" (1967: 9). Aunque no se dijera con claridad, la primacía del Estado que se deducía de estas palabras expresaba su carácter antiliberal, pese a que el general defendiera a Locke en su obra soslayando el hecho de que éste primaba al individuo sobre el Estado.

15 "Ya viejo, respetado por todos [...] Hobbes temería aún, sintiéndose amenazado como siempre por el espectro de la inseguridad que le perseguiría toda la vida pero que, por otro lado, lo había sustentado en la admirable construcción lógica de su monolítica sistematización política" (1967: 9). 
El temor de que desapareciera la civilización cristiana y la democracia inspiraba a de Couto e Silva y, en principio, a buena parte de los defensores de la Doctrina de Seguridad Nacional. Él, como buena parte de los militares adscritos a ella, se formó en el liberalismo y en el concepto de democracia, si bien creía -y creían parte de los demás- que debían definirse sus fundamentos de nuevo en el mundo de la amenaza comunista. Creía que el ideal liberal del Estado de Derecho había muerto en la Segunda Guerra Mundial y su propia experiencia, como la de otros oficiales, construyó su pensamiento. Había combatido al totalitarismo en los campos de batalla de Europa. Sabía de sus desastrosos efectos y de su perversa naturaleza. ¿Qué pasó entonces para amparar doctrinas como la Doctrina de Seguridad Nacional? Son reveladoras unas palabras de Ferreira para entender este problema ${ }^{16}$. Dicho de otro modo: creía que para garantizar la libertad y la seguridad de las gentes en un mundo que parecía amenazado de muerte por la onda expansiva de la revolución y del comunismo, las sociedades y las democracias debían organizarse como las fuerzas armadas, en donde los oficiales velan por el bienestar de la tropa.

Lo que se deduce de esto es que las fuerzas armadas debían actuar -y así lo hicieron- como un partido político (Rivas, 2009a: 284-286), cuya misión era organizar la sociedad. Este principio -quizá bienintencionado, pero peligroso- contradice la acción cotidiana de los regímenes de Seguridad Nacional, porque para ellos el pueblo no era el sujeto de la historia de la nación, sino el objeto de la acción del Estado cuyo fin era garantizar la grandeza del país y su supervivencia. No es de extrañar esta contradicción, pues en los partidarios de la Doctrina de Seguridad Nacional era habitual. Se condenaba a veces a Hobbes pero se aceptaba su pensamiento e incluso se lo malinterpretaba; se atacaba al liberalismo pero se aceptaba -formalmente, al menos, aunque en contadas ocasiones- la democracia representativa; se defendía a Occidente pero se criticaba al lucro. En realidad, las fuerzas que querían representar a la nación y al Estado y dirigirlo en supuesto beneficio de todos no se identificaban con ningún sector de la sociedad civil. De ahí que la Doctrina de Seguridad Nacional fuera más bien una doctrina de la seguridad del Estado. La seguridad afectaba a todos los aspectos de la vida social, pues en todas partes había amenazas. La Seguridad Nacional era una responsabilidad de todos los ciudadanos y cada uno de ellos debía estar implicado en ella. Todos los ciudadanos podían crear problemas de seguridad y todos podían contribuir a resolverlos, tal y como decían algunas leyes de algunos países iberoamericanos o algunos altos mandos de sus ejércitos. Con esa claridad se recogía, sin ir más lejos, en el artículo 4 de la Ley de Seguridad Nacional del 2 de abril de 1976 de la República del Ecuador; o el coronel chileno Bacigalupo (1976), cuando afirmaba que "toda la población del estado tiene una participación ineludible en este proceso", insistía en que la Seguridad Nacional no era un problema exclusivo de las fuerzas armadas.

16 "Incapaz [...] de entender la antinomia [...] Comunismo versus Democracia, y de proponer teóricamente un nuevo sistema en el que la "seguridad jurídica" se complemente con una eficacia y una seguridad nacional, tiene como único punto de referencia, cuando se trata de defender la libertad, [...] la libertad de que gozan los oficiales en el cuerpo de oficiales, y que los regímenes nazi y comunista suprimieron al subordinar el Ejército al Partido" (1970: 174). 
Por ello los militares que defendían la Doctrina de Seguridad Nacional monopolizaban el poder hasta la extenuación. Al fin y al cabo los pueblos sin una historia -aparentemente- desarrollada aplicaban una idea de la democracia en la que el Estado de Derecho era residual o inexistente, pues quedaba subordinado a la seguridad del país (González, 2007: 153). Si se tiene en cuenta que en aquellos años -hasta el fin de la Guerra Fría- el concepto primordial de seguridad tenía carácter militar, se entiende mejor la Doctrina de Seguridad Nacional y su apego a las fuerzas armadas. Es más, la Seguridad Nacional necesitaba de la protección ilimitada y permanente del Estado para combatir a las organizaciones marxistas.

Vista la naturaleza de la Doctrina de Seguridad Nacional, se entiende el porqué de la obsesión con la seguridad y con el hecho de que todo debiera estar al servicio de la guerra para frenar la insurgencia izquierdista. No en vano el general brasileño Couto e Silva no entendía de otra manera la guerra contra el comunismo, pues ese conflicto era la guerra por la supervivencia de Occidente (Couto e Silva, 1967: 190-200, 225-257) -es decir, era la guerra absoluta-. De la misma manera el general Pinochet libraba una guerra absoluta contra el comunismo, tal y como lo recordaba en el discurso leído el 11 de septiembre de 1973 tras el asalto al Palacio de La Moneda. Decía que "como otros países del mundo y especialmente de América Latina, Chile ha sufrido el embate del marxismo-leninismo y ha decidido enfrentarlo y combatirlo hasta su total derrota" (Pinochet, 1973). Con esta doctrina política sólo podía concebirse una guerra de eliminación total, habida cuenta de la perfidia privativa del enemigo y de los males que acarrearía no acabar con él. El error de no eliminarlo supondría el advenimiento de la guerra generalizada, es decir, el enfrentamiento de los bloques en una guerra cuyos medios acabarían con los combatientes. Pinochet afirmó en aquel discurso que el marxismo era una doctrina intrínsecamente perversa, lo que significaba que todo lo que de ella brotase, por sano que se presentase en apariencia, estaba carcomido por el veneno que corroe su raíz. "Esto es lo que quiere decir que su error sea intrínseco y, por lo mismo, global, en términos que no cabe con él ningún diálogo o transacción posible” (Pinochet, 1973).

Para poderse enfrentar con éxito al enemigo era imprescindible que no se diferenciaran lo civil y lo militar. Si en el siglo XIX se formuló una separación muy clara entre ellos, en el mundo de la Seguridad Nacional no había diferencia entre la sociedad civil y la militar. Tal asimilación la presintieron los teóricos de la guerra total -como Ludendorf- pero esta nueva idea fue, en parte, obra de los Estados Unidos desde después de la Segunda Guerra Mundial ${ }^{17}$. Las fuerzas armadas ya no eran el ejército de ciudadanos surgido de la Revolución Francesa, pues formaban un cuerpo autónomo con su propia legislación y su propia justicia. Sin embargo, a ojos de los doctrinarios de la Seguridad Nacional, parecían ser la única

17 La desaparición progresiva de barreras entre lo civil y lo militar comenzó en los Estados Unidos. Allá la primera etapa del proceso de unión de lo civil y lo militar fue la creación del Consejo de Seguridad Nacional y de una nueva burocracia que unificó la diplomacia y la guerra -las actividades del Departamento de Estado y del Departamento de Defensa-. A ésta le siguió la integración de los grandes sectores de la economía hasta el punto de formar el complejo militar-industrial -que incluso Eisenhower señaló como un gran peligro para su propia sociedad-. Se amplió con la unión a lo anterior del mundo universitario y, más tarde, del mundo sindical. Sin embargo, los Estados Unidos jamás dejaron de ser una democracia, ni siquiera en los años más duros de la Guerra Fría. Esta fue la gran diferencia con buena parte de los países de Iberoamérica. 
representante legítima de la nación. Si a partir del siglo XIX las fuerzas armadas, como dijo De Vigny en una conocida frase, eran una nación dentro de la nación (De Vigny, 1962), los ejércitos de los regímenes de Seguridad Nacional se convirtieron en la nación misma o, al menos, en su única representante. Las siguientes palabras, escritas por los mandos militares alzados en armas, en su Mensaje al Pueblo Argentino de 1966, pueden aplicarse al resto del continente porque su sustancia es válida para todos los regímenes de nuevo cuño que aparecieron por aquel entonces ${ }^{18}$. Su intención era -decíanconstruir una verdadera democracia que sirviera a la grandeza nacional.

En los regímenes iberoamericanos de Seguridad Nacional la unión mencionada representaba el ideal porque, si se lograba, toda la nación estaría comprometida en una sola estrategia - estrategia impuesta por las necesidades de la Guerra Fría, que era total, generalizada y absoluta-. La estrategia nacional articulaba el poder nacional con miras a la Seguridad Nacional y así se lograba una síntesis perfecta, esencial. Esta simplicidad era consecuencia de la unidad de la base de la que todo partía: el concepto de guerra que se estudia en este artículo. La seguridad nacional, por tanto, significaba no sólo la protección militar de la nación, sino de todas las manifestaciones de la vida nacional, en lo político, lo económico, lo social o lo cultural. La defensa militar de la nación se trasladaba a las relaciones políticas y sociales. El general Lyra Tavares dijo ya en 1962 que la seguridad nacional no consistía sólo en un asunto relacionado principalmente con la defensa del territorio, sino que se extendía a preservar el organismo nacional de los ataques de todo lo que contribuyera a debilitar la nación (Lyra, 1962). En esto quedaba incluido el enemigo interior. El militarismo, entonces, se justificaba racionalmente porque aparecían las condiciones propicias para que las tropas pudieran actuar fuera de su ámbito. Si en el Egipto de los jóvenes oficiales revolucionarios nasseristas se había justificado la intervención para luchar contra el feudalismo y la corrupción, en América Latina nacía para enfrentarse al comunismo (Riera, 2010). Y las fuerzas armadas, -en donde había disciplina, jerarquía, centralización del mando y espíritu de cuerpo- eran el instrumento adecuado para hacerle frente. Estas características eran, precisamente, las raíces del aislamiento y de la autosuficiencia de los ejércitos ${ }^{19}$ en esos años.

Este razonamiento y el comportamiento que se derivaba de él poco tenían que ver con las clásicas intervenciones de los militares en Iberoamérica. Aunque las interpretaciones habituales afirmaban que la intervención militar era una forma perversa de control de la sociedad -ejecutada por las "manos armadas" de las elites sociales-, en realidad eran la respuesta a los deseos de los sectores medios ascendentes que querían introducir reformas limitadas en la sociedad, siempre que es-

18 "Hoy, como en todas las etapas decisivas de nuestra historia, las Fuerzas Armadas, interpretando el más alto interés común, asumen la responsabilidad irrenunciable de asegurar la unión nacional y posibilitar el bienestar general, incorporando al país los modernos elementos de la cultura, la ciencia y la técnica, que al operar una transformación lo sitúen donde le corresponde por la inteligencia y el valor humano de sus habitantes y las riquezas que la Providencia depositó en su territorio [...] para restablecer una auténtica democracia representativa en la que impere el orden dentro de la ley, la justicia y el interés del bien común, todo ello para reencauzar al país por el camino de su grandeza y proyectarla hacia el exterior" (VV.AA., 1966: 4 y 7).

19 Al respecto es muy interesante la obra de Samuel Edward Finer titulada The Man on Horseback, publicada en Londres por Pall Mall Press en 1962. 
tuvieran controladas y fueran de signo conservador (Zirker, 1998: 67-86). Es cierto que las fuerzas armadas parecían un cuerpo separado de la sociedad que tenía sus propias reglas, pero esta visión tan sesgada acabó imponiéndose como si fuera la única verdadera. La verdad es que los militares en Iberoamérica sólo habían tenido autonomía relativa (Varas, 1988) y tenía razón Imaz (1964) cuando decía que, a veces, los grupos sociales intentaban aprovecharse del ejército para sus propios fines, precisamente porque las fuerzas armadas no solían perseguir un fin gubernamental directo y permanente. Con la Doctrina de Seguridad Nacional eso cambió al ser la institución militar como tal, al completo, la que asumía el poder para reorganizar el Estado y la sociedad. Era un fenómeno nuevo alejado del viejo caudillismo civil y militar (Cardoso, 1985: 71-72).

Por si no fuera claro todo lo anterior, los doctrinarios de la Seguridad Nacional afirmaban que toda guerra contra el comunismo era necesariamente una guerra por la supervivencia (Cortés, 1976: 121-122). Le aplicaban los conceptos de guerra total de Ludendorf y de guerra generalizada del Estado Mayor de los Estados Unidos. Cambiaban los medios, pero el concepto de guerra seguía siendo el mismo: era una guerra absoluta, si bien ésta no era un tipo ideal e históricamente imposible al modo de Clausewitz, sino la plasmación en la vida real del peor tipo de guerra posible, la de destrucción completa del enemigo. Y precisamente por esto la guerra se imponía finalmente a la política -tal y como decía Ludendorf- y, de alguna manera, la absorbía y la hacía desaparecer -como demostraban los hechos en los sistemas de Seguridad Nacional $^{20}$. Muy posiblemente el rigor de los sistemas políticos aplicados en los países que padecieron la Doctrina de Seguridad Nacional no se debía a circunstancias accidentales, sino a la concepción de la guerra que mantenían. Al igual que Von Clausewitz creía que un buen militar no debía guiarse con reglas, sino saber qué era la guerra absoluta y, de esa manera, tener las ideas claras en la guerra real para adaptarse bien a las circunstancias inmutables -es el espíritu que se recoge en toda su obra esencial, De la guerra-, los militares que aplicaban la Doctrina de Seguridad Nacional estaban inspirados por razones parejas. Por eso no importaba que la doctrina estuviera poco definida o fuera confusa; lo único necesario era que supiera orientar la acción y que diera claves para saber cómo actuar en la guerra contra el enemigo. Del mismo modo Von Clausewitz pensaba que las guerras absolutas, si bien eran imposibles, casi se habían plasmado históricamente en las guerras napoleónicas, es decir, en las guerras revolucionarias de su tiempo. Por eso los doctrinarios de la Seguridad Nacional temían tanto a las guerras revolucionarias o a lo que ellos tenían por tales, y aplicaban contra ellas los principios citados.

20 Es normal que en los países que precisan consolidar el Estado se tienda a usar el poder militar para solucionar problemas de toda índole (Griffiths, 2007: 105). 


\section{A modo de colofón y cierre}

Con estas proposiciones se tiene más clara la idea de la que partían los regímenes de Seguridad Nacional. Quienes los capitaneaban ejercían el poder y razonaban de la manera que se expondrá a continuación. Como la guerra, en caso de que estallase, era inevitablemente de destrucción total, debía evitarse a toda costa sin importar los medios empleados; así que era mejor excederse en la represión que quedarse corto, pues de lo contrario podría llegar la guerra que se quería evitar. Al ser una guerra por la supervivencia toda la población debía estar involucrada, pues los valores de la nación eran los que habían de asumir sin excepción los ciudadanos. Así que si la guerra absorbía todos los esfuerzos, la política desaparecía y debía dirigirla quien dirigiera la guerra. Es más, si el peligro era constante, el control también debía de serlo. Y si la violencia de la guerra amenazaba a la vida colectiva, sólo la violencia que mantenía alerta a las gentes era instrumento útil. En definitiva, era el ideario del Estado autoritario y despótico. Ya fuera levemente malinterpretado o seguido a pies juntillas, parte del pensamiento de Von Clausewitz y sobre todo de Ludendorf se instaló en las Américas.

Parte de la doctrina militar convencional infló, además, la importancia de los factores psicológicos desde los años sesenta, y los militares de la Seguridad Nacional, que estaban convencidos de que la suerte de la guerra se jugaba en el plano psicológico, la sobrevaloraron aún más. Por ello daban una importancia extrema al control de todos los factores que podían afectar a la moral de la población y a su voluntad de luchar contra el comunismo. Una voluntad única y común era imprescindible para la victoria y la disidencia debía perseguirse para evitar que la resistencia se agrietara. Del mismo modo crear la discordia entre el enemigo era una fórmula de subversión estratégica que quería romper el equilibrio de fuerzas. Unas palabras del coronel chileno Cortés resumen discretamente estos criterios. Aseguraba que el potencial de guerra se transformaba en potencial militar "de acuerdo con la voluntad de los individuos de trabajar más, consumir menos, economizar más, aceptar molestias y peligros y conformarse con una mayor dirección de sus vidas por parte del gobierno, ya sea en forma voluntaria o por compulsión" (Cortés, 1976: 137).

Para lograr todo esto las fuerzas armadas ejercían el poder sin remisión. No había diferencias de naturaleza entre el poder militar y todas las otras formas de acción del Estado pues, en realidad, todo estaba militarizado. En los regímenes de Seguridad Nacional los ejércitos estaban plenamente integrados en la política y el poder militar no era sino una parte del poder militar generalizado ejercido por un cuerpo especializado, las fuerzas armadas. El efecto de esto fue que las relaciones sociales se caracterizaban por el miedo, por la amenaza política y por la represión y que los conflictos sociales agudos podían llegar incluso a transformarse en guerra. De hecho, los regímenes de Seguridad Nacional lograron transformar la representación colectiva de la violencia política sin hacer distinción de clases ni grupos sociales. Si en América Latina la represión se ejercía tradicionalmente en grupos concretos -indígenas, campesinos, mineros...- la represión política e ideológica traspasó las viejas barreras. Su carácter aparentemente arbitrario creó una amenaza permanente cuyo efecto fue el miedo crónico y los defensores y acólitos de la guerra total recogieron estos usos en el corpus teórico de la guerra generalizada. 
No obstante, lo que ocurría era que la guerra librada por los ejércitos iberoamericanos era distinta de la guerra atómica. Y esta guerra era la que se estudiaba y la que definía los asuntos de la Seguridad Nacional en los Estados Unidos. Este "pequeño" problema se solucionó con una idea conocida y, al mismo tiempo, malinterpretada, que era la idea de Guerra Fría. Entre la guerra atómica y la Guerra Fría sólo existía -según los teóricos de la Seguridad Nacional- una diferencia de grado y no de naturaleza. De forma que el concepto de guerra total o generalizada podía aplicarse también a la Guerra Fría, que era otro asunto clave de la teoría de la Seguridad Nacional. Se diría, entonces, que las palabras de Gaston Bouthoul pensadas para la guerra atómica pueden aplicarse a las sociedades en las que se vivían las asperezas de la Doctrina de Seguridad Nacional, que violentó la democracia que la precedía en las naciones iberoamericanas: “La destrucción está en todas partes [...] Los terrores apocalípticos son cada vez más actuales. Definitivamente instaurados hacen de nuestra época el Siglo de Damocles" (Bouthoul, 1970a: 212-213).

\section{Bibliografía}

Aron, R. (1993a): Pensar la guerra, Clausewitz. La edad europea, tomo I. Madrid: Ministerio de Defensa.

-(1993b): Pensar la guerra, Clausewitz. La edad planetaria, tomo II. Madrid: Ministerio de Defensa.

Bacigalupo, E. (1976): “El Estado y la Seguridad Nacional”, Seguridad Nacional (1), pp. 10-21.

Bouthoul, G. (1970a): Ganar la paz- evitar la guerra. Barcelona: Plaza y Janés.

- (1970b): Traité de Polémologie. Paris: Payot.

- (1971): La guerra. Barcelona: Oikos-Tau.

Cardoso, F. H. (1985): “Caracterización de los regímenes autoritarios”, en Collier, D. (ed.): El nuevo autoritarismo en América Latina. México: FCE.

Collins, J. M. (1970): The Great Strategy. Maryland: Naval Institute Press.

Clausewitz, C. V. (2005): De la guerra. Madrid: La Esfera de los Libros.

Comblin, J. (1979): La Doctrina de la Seguridad Nacional. Santiago de Chile: Arzobispado de Santiago-Vicaría de la Solidaridad.

Couto e Silva, G. (1967): Geopolítica de Brasil. Río de Janeiro: José Olympio.

Cortés, G. (1976): La Seguridad Nacional como Objetivo de Gobierno en Nuestro Camino. Santiago de Chile: Editorial Encina.

Delmas, C. (1970): Histoire des Projects D’Unifications Politique de L’Europe (1815-1970). Bruxelles: Uga.

De Vigny, A. (1962): Servitude et Grandeur Militaires. Paris: Garnier Frères. 
Ferreira, O. (1970): “La geopolítica y el Ejército brasileño”, en Beltrán, V. (ed.): El papel político y social de las Fuerzas armadas en América Latina. Caracas: Monte Ávila Editores.

Finer, S. (1962): The Man on Horseback. London: Pall Mall Press.

Freedman, L. (1989): The Evolution of Nuclear Strategy. London: MacMillan.

Gilbert, F. (1986): “Machiavelli” en Paret, P.: Makers of Modern Strategy: from Machiavelli to the Nuclear Age. Princeton: Princeton University Press.

González, J. (2007): “Las preocupaciones en el Cono Sur sobre un concepto amplio de seguridad”, en Sepúlveda, I. (coord.): Seguridad Humana y nuevas políticas de Defensa en Iberoamérica. Madrid: Instituto Universitario General Gutierrez Mellado - UNED.

Griffiths, J. E., (2007): “Seguridad Hemisférica en América Latina: Alcances y Proposiciones”, Globalization, Competitiveness \& Governability, vol. 1, no 1, Washington D.C.: Georgetown University. Disponible en: http://gcg.universia.net/ pdfs_revistas/articulo_66_1195588149605.pdf > [Consultado el 1 de marzo de 2010].

Grocio, H. (1925): Del derecho de la guerra y de la paz. Madrid: Reus.

Imaz, J. L. (1964): Los que mandan. Buenos Aires: Eudeba.

Kalb, M. y Kalb, B. (1975): Kissinger. New York: Dell Publishing.

Keegan, J. (1995): Historia de la guerra. Barcelona: Planeta.

Kershaw, I. (2000): Hitler, 1936-1945. Barcelona: Ediciones Península.

Liddell Hart, B. (1931): The Ghost of Napoleon. New Haven: Yale University Press.

- (1946): La estrategia de aproximación indirecta. Barcelona: Iberia-Joaquín Gil.

López, E. (1985): “Doctrinas militares en Argentina (1932-1980)”, en Moneta, C. et al.: La reforma militar. Buenos Aires: Legasa.

Ludendorf, E. (1936): La Guerre Totale. Paris: Flammarion.

Lyra, A. (1962): “Coompreensa de Segurança Nacional”, Forum Roberto Simonsen.

Maquiavelo, N. (1998): El arte de la guerra. Madrid: Tecnos.

Martínez, A. (dir.) (2001): Diccionario del arte de la guerra. Barcelona: Planeta.

Pavón, J. (1971): La subversión contemporánea. Madrid: Narcea S. A. Ediciones.

Pinochet, A. (1973): Discurso tras el asalto al Palacio de La Moneda (documento sin fecha ni datos identificativos). 
Ramírez, J. M. (1983): “Proliferación nuclear: ¿Alternativa o quiebra de un sistema internacional en crisis?”, Anuario de la Facultad de Derecho, vol. 2, pp. 471-507.

Rey, P. y Rivas, P. (2007): Orden internacional y conflictos. Madrid: Biblioteca Nueva.

Riera, E. (entrevista hecha en Buenos Aires a un oficial de alto rango de las Fuerzas Armadas, septiembre de 2010. El nombre -Edgardo Riera- es falso y se ha cambiado por petición expresa del entrevistado.)

Rivas, P. (2009a): “El Estado militar en América del Sur: intervencionismo, caudillismo y fuerzas armadas”, en Política y Estrategia, n¹14, pp. 271-291.

- (2009b): Doctrina de Seguridad Nacional y regímenes militares en Iberoamérica. Alicante: Club Universitario.

Schmitt, C. (1998): El concepto de lo político. Madrid: Alianza Editorial.

Sohr, R. (2003): Claves para entender las guerras. Barcelona. Mondadori.

Tucker, R. y Hendrickson, D. (1990): “Thomas Jefferson and American Foreign Policy”, Foreign Affairs, vol. 69. no 2. Washington, Council on Foreign Relations.

Varas, A. (coord.) (1988): La autonomía militar en América Latina. Caracas: Nueva Sociedad.

VV.AA. (1966): Revolución Argentina. Buenos Aires: Separata del Boletín Oficial, 8 de julio.

Zirker, D. (1998): “José Nun’s “Middle-Class Military Coup in Contemporary Perspective: Implications of Latin America’s Neoliberal Democratic Coalitions”, Latin American Perspectives, no 25, vol. 5, pp. 67-86. 